\title{
Pengaruh Video Persalinan Normal terhadap Kecemasan Ibu Hamil Menghadapi Persalinan di Wilayah Kerja Puskesmas Pangaribuan Kecamatan Pangaribuan Kabupaten Tapanuli Utara
}

\author{
Indah Dewi Sari*, Sulastri Pakpahan \\ Jurusan D4 Kebidanan Institut Kesehatan Helvetia Medan, Indonesia \\ *Corespondence email: indahdewi@helvetia.ac.id, sulastripakpahan28@gmail.com
}

\begin{abstract}
Abstrak. Kecemasan cenderung terjadi pada Ibu primigravida karena takut menghadapi persalinan. Sekitar $80 \%$ ibu primigravida mengalami kecemasan yang meningkat, dan akibat kecemasan dapat mengakibatkan komplikasi pada ibu dan janin. Salah satu upaya yang dapat dilakukan untuk menurunkan kecemasan tersebut dapat dengan cara menonton video persalinan normal. Penelitian bertujuan untuk mengetahui Pengaruh Video Persalinan Normal Terhadap Kecemasan Ibu Hamil Menghadapi Persalinan di Wilayah Kerja Puskesmas Pangaribuan Kecamatan Pangaribuan Kabupaten Tapanuli Utara . Jenis penelitian ini menggunakan Jenis Penelitian Quasi Eksperiment dengan rancangan yang digunakan adalah One Group Pretest-Postest Design. Sampel penelitian ini adalah 10 orang Ibu hamil yang diukur sebelum dan sesudah intervensi menonton video persalinan normal. Berdasarkan hasil uji statistik analisis data menggunakan analisa univariat dan bivariat. Analisa bivariat menggunakan uji Wilcoxon Rank Test, diperoleh p value (Sig.2-tailed) sebesar 0,006 < $2: 0,05$, maka dapat disimpulkan bahwa terdapat Pengaruh Video Persalinan Normal Terhadap Kecemasan Ibu Hamil Menghadapi Persalinan di Wilayah Kerja Puskesmas Pangaribuan Kecamatan Pangaribuan Kabupaten Tapanuli Utara Tahun 2020. Ada pengaruh antara video persalinan normal terhadap kecemasan ibu hamil menghadapi persalinan di Wilayah Kerja Puskesmas Pangaribuan Kecamatan Pangaribuan Kabupaten Tapanuli Utara . Saran bagi petugas kesehatan agar memberikan pendidikan kesehatan kepada ibu primigravida dalam menghadapi persalinan sehingga dapat mengurangi rasa ketakutan dan tingkat kecemasan ibu hamil menjelang persalinannya.
\end{abstract}

Kata Kunci: Video Persalinan Normal; Kecemasan

Abstract. Primigravida mothers in facing delivery would experience anxiety. Anxiety in pregnant women increases in the third trimester which can lead to complications for both the mother and the fetus. $80 \%$ of primigravida mothers experience anxiety just before delivery. Efforts that can be made to reduce anxiety can be by watching videos of normal childbirth. The aim of the study was to determine whether there was an effect of video of normal delivery on anxiety of pregnant women in facing childbirth in the Pangaribuan Health Centre, Pangaribuan District, North Tapanuli Regency in 2020.This study used a Quasi-Experimental Research type with the design used was One Group Pretest-Postest Design. The sample of this study were 10 pregnant women who were measured before and after the intervention watching normal childbirth videos. Based on the results the data analysis used univariate and bivariate analysis. Bivariate analysis using the Wilcoxon Rank Test, obtained a p value (Sig.2-tailed) of .006 $<\alpha: 0.05$, it can be concluded that there is an effect of Normal Delivery Videos on Anxiety of Pregnant Women Facing Childbirth in the Pangaribuan Health Centre, Pangaribuan District, District North Tapanuli 2020. These results conclude that there is a significant effect between normal delivery videos on the anxiety of pregnant women facing childbirth in the Pangaribuan Public Health Centre, Pangaribuan District, North Tapanuli. Suggestions for health care workers to provide more information to primigravida mothers about labor preparation to reduce feelings anxiety of pregnant women facing childbirth.

Keywords: Normal Childbirth; Videos; Anxiety

\section{PENDAHULUAN}

Program pemerintah untuk mencegah Angka Kematian Ibu dan amgka kematian bayi salah satunya adalah melakukan upaya meningkatakan Asuhan kehamilan dan persalinan agar persiapan kelahiran dapat ditangani dengan baik dan mengurangi tingkat kecemasan dalam menghadapi persalinannya.

Sebagian besar perempuan menganggap kehamilan dan persalinan adalah hal yang menakutkan, sehingga muncul kecemsan yng berlebihan, apalagi ibu primigravida atau ibu yang hamil untuk pertama kalinya, karena proses persalianan sesuatu hal yang baru sehingga persalinan dianggap peristiwa yang menakutkan dan menjadi resiko yang sangat besar untuk menentukan kehidupannya. (Arafah CT \& Aizar E,
2012)

Pada Kehamilan trimester ketiga, kecemasan pada ibu primigravida meningkat dibandingjkan dengan trimester sebelumnya. $80 \%$ mengalami kecemasan menjelang persalianan. Banyak kekhawatiran yang dialami oleh ibu terutama kondisi bayi dan dirinya sendiri. Kesiapan psikologis adalah salah satu upaya untuk menurunkan tingkat kecemasan menghadapi persalinannya agar mengurangi komplikasi pada ibu dan bayi akbat kecemasan tersebut. (Mandala W, 2014)

Angka Kematian Ibu selama dan setelah kehamilan dan persalinannya pada tahun 2017 sangat tinggi sekitar 295.000 perempuan meninggal. Afrika sub Sahara dan Asia Selatan 86\% (254.000). Sub Sahara Afrika sekitar dua pertiga (196.000) dari kematian ibu. 
Data tersebut dikutip dari WHO. Sementara Pada Tahun 2015 menurun dari 43\% menjadi 303 per $\mathrm{KH}$ jumlah perempuan yang meninggal karena komplikasi selama kehamilan dan persalinannya. (Kartikasari E, 2015)

Tingkat kecemasann yang sering terjadi pada kategori sedang dan berat sekitar 47,2\%, resikonya menyebabkan terjadinya solusio plasenta berkisar $1,29 \%$ pada cemas ringan, 1, 63\% cemas sedang dan 2,30 cemas berat. Akibat laim tingkat kecemasan menghadapi persalinan akan berpengaruh kepada kesehatan ibu dan janin. Data menunjukan $42,8 \%$ terjadi pada primigravida dan $29,5 \%$ pada Multigravida, akibatnya mengalami tingkat nyeri serta persalianan yang membutuhkan waktu yang lama (Lagora $R, 2014)$.

Pada Tahun 2015 Angka kematian Ibu di Indonesia terjadi penurunan menjadi 305 kematian ibu per 100.000 kelahiran hidup. Sebanyak 33,07\% kematian ibu akibat hipertensi, 27,3\% perdarahan obstetrik, $15,7 \%$ komplikasi non obstetrik, 12,04\% komplikasi obstetrik lainnya, 6,06\% infeksi kehamilan, 4,81\% karena penyebab lainnya.(Lagora R, 2014)

Penyebab kematian tersebut salah satunya karena ibu hamil mengalami kecemasan menghadapi persalinannya, terdapat $107.000(28,7 \%)$ kecemasan terjadi pada ibu hamil dalam menghadapi persalinan. Sesuai hasil penelitian Novitasari (2015), menyatakan bahwa 66,2\% kecemasan terjadi pada ibu primigravida dibandingkan pada ibu multigravida sebesar 42,2\%. (Lagora R, 2014)

Profil Kesehatan kabupaten/kota, pada tahun 2016 Angka kematian ibu sebanyak 239 kematian. Seperti di Sumatera Utara biladikonversi AKI sebesar 85/100.000 $\mathrm{KH}$, sementara AKI di Sumatera Utara sebesar 328/100.000 KH, Jumlah tersebut berbeda dan belum menggambarkan jumlah AKI yang sbenarnya. Survei AKI dan AKB yang dilakukan oleh Dinas Kesehatan provinsi Sumatera Utara dengan mahasiswa FKM Universitas Sumatera utara, menyebutkan bahwa sepuluh tahun yang lalu AKI di SUMUT sebesar 268/100.000 KH, dari hasil kematian menunjukan bahwa AKI di SUMUT belum mengalami penurunan sampai Tahun 2016. (Dinkes P. Profil Kesehatan Sumut, 2018)

Berdasarkan data profil kesehatan Taput pada tahun 2017, jumlah kematian ibu sebanyak 8 orang diantaranya 2 orang ibu nifas, 3 orang ibu hamil dan ibu bersalin 3 orang, kemudian mengalami penurunan di Tahun 2018, AKI menurun menjadi 4 orang, ibu hamil 1 orang, bersalin 3 orang. Upaya yang dilakukan oleh Dinas Kesehatan Kab. Tapanuli Utara untuk menurunkan AKI dengan adanya kelas ibu hamil disetiap wilayah kerjaTapanuli Utara yang dibimbing oleh petugas kesehatan puskesmas dengan memberikan pengetahuan dan keterampilan melalui pertemuan kepada ibu hamil tentang asupan makananyang bergizi untuk menghindari kekurangan energi kronis. (Dinkes Taput, 2018)
Hal- hal yang dapat mengurangi rasa cemas atau kecemasan adalah dengan cara memberikan penyuluhan menggunakan leaflet, brosur, demonstrasi dan video audiovisual tentang persalinan normal dengan itu rasa cemas ibu hamil menghadapi persalinan akan berkurang. Ibu hamil dapat memperoleh video persalinan dari berbagai sumber media sosial seperti mengakses video persalinan normal melalui youtube, facebook atau dengan adanya DVD yang bisa kita putar melalui laptop ataupun pada Televisi yang memudahkan ibu hamil menonton video persalinan normal. (Kartikasari E, 2015)

Video persalianan merupakan salah satu cara mengurangi tingkat kecemasan menghadapi persalinan. Dengan melihat video dapat menambah pengetahuan ibu mengetahui proses kelahiran terjadi. Ibu hamil dapat mempersiapkan diri menghadapi persalinannya karena melihat video persalianan membantu menvisualisasikan diri untuk melihat proses bayi lahir dari jalan lahir selama persalinan. Video persalianan mengurangi tingkat kecemasan ibu karena ibu meiliki pandangan positif dan persiapan yang lebih matang untuk mempersiapkan kelahiran. (Hayati F, 2018)

Sesuai dengan hasil penelitian yang telah dilakukan tentang kecemasan ibu menghadapi persalinan, didapatkan hasil $p<0,05$, artinya video persalianan memiliki hubungan mengurangi tingkat kecemasan dalam menghadapi persalianan. Audiovisual proses persalianan mengurangi tingkat kecemasan pada ibu primigravida sebelum dan setelah menonton videonya, seperti ibu mengalami cemas berat (53\%) sebelum menonton video persalinan, dan setelah menonton videp persalianan tingkat kecemasan yang dialami ibu menjadi kategori cermas sedang $(86,7 \%)$. (Arafah CT \& Aizar E, 2012)

Penelitian yang sama juga berpengaruh terhadap tingkat kecemasan ibu dalam menghadapi persalinan. Penelitian ini tidak hanya memberikan video persalianan saja tetapi memberikan konseling pada saat yang bersamaan. Hasil menunjukan ada pengaruh tingkat kecemasaan setelah d berikan perlakuan kedua aspek tersebut. Tingkat pendidikan yang paling berpengaruh terhadap tingkat kecemasan ibu primigravida pada saat menghadapi persalinan. (Lagora R, 2014)

Hasil Observasi pada saat survei awal di Puskesmas Pangaribuan, dengan tekhnik wawancara dari 10 orang ibu hamil, 4 orang mengatakan Takut dan cemas dalam menghadapi persalinan, dengan beragam alasan ada yang mengatakan takut terjadi kematian saat melahirkan, takut akan rasa nyeri yang hebat sasat bersalin, takut karena masih pertama kali berada diruang bersalin dan cemas tidak dapat bersalin dengan lancar dan 6 orang mengatakan tidak terlalu takut dan merasa cemas menghadapi persalinannya.

Hasil latar belakang diatas maka penulis ingin melakuan penelitian tentang bagaimana "Pengaruh Video Persalinan Normal Terhadap Kecemasan Ibu Hamil Menghadapi Persalinan Di Wilayah Kerja 
Indah Dewi Sari dan Sulastri Pakpahan, Pengaruh Video Persalinan Normal terhadap Kecemasan Ibu Hamil Menghadapi Persalinan di Wilayah Kerja Puskesmas Pangaribuan Kecamatan Pangaribuan Kabupaten Tapanuli Utara

Puskesmas Pangaribuan Kecamatan Pangaribuan Kabupaten Tapanuli Utara Tahun 2020”.

\section{METODE}

Penelitian ini dilakukan dengan desain pendekatan Pretest dan Postest atau penelitian dilakukan sebelum dan sesudah perlakuan. Quasy Experiment adalah Desain penelitian yang digunakan pada penelitian ini. Penelitian dilakukan di Wilayah Kerja Puskesmas Pangaribuan Kecamatan Pangaribuan Kabupaten Tapanuli Utara karena tempatnya memungkinkan dan terjangkau oleh peneliti untuk melakukan penelitian.. Waktu penelitian pada bulan April sampai bulan Oktober, dimulai dari survei awal, pengajuan judul, pengambilan data, seminar proposal, penelitian sampai sidang hasil. (Notoatmodjo, 2016)

Populasi dalam penelitian ini adalah ibu hamil di Wilayah Kerja Puskesmas Pangaribuan sebanyak 100 orang. Sampel adalah sebagian atau wakil populasi yang diteliti. Teknik pengambilan sampel dalam penelitian ini adalah non probability sampling dengan teknik purpose sampling. Purpose. Sampel yang digunakan penelitian sebanyak 10 orang.

\section{HASIL}

\section{Analisis Univariat}

Tabel 1. Distribusi Frekuensi Kecemasan Ibu Hamil Menghadapi Persalinan Sebelum dan sesudah Menonton

Video Persalinan Di Wilayah Kerja Puskesmas Pangaribuan Kecamatan Pangaribuan Kabupaten Tapanuli Utara

\begin{tabular}{lcccc}
\hline Kecemasan Ibu Hamil & \multicolumn{2}{c}{ Pretest } & \multicolumn{2}{c}{ Posttest } \\
\cline { 2 - 5 } Menghadapi Persalinan & $\mathbf{f}$ & $\mathbf{\%}$ & $\mathbf{f}$ & $\mathbf{\%}$ \\
\hline Tidak Cemas & 0 & 0 & 3 & 30 \\
Cemas Ringan & 1 & 10 & 7 & 70 \\
Cemas Sedang & 6 & 60 & 0 & 0 \\
Cemas Berat & 3 & 30 & 0 & 0 \\
Total & $\mathbf{1 0}$ & $\mathbf{1 0 0}$ & $\mathbf{1 0}$ & $\mathbf{1 0 0}$ \\
\hline
\end{tabular}

Berdasarkan hasil pre-test diketahui bahwa kecemasan ibu hamil menghadapi persalinan sebelum menonton video persalinan normal adalah Cemas Ringan sebanyak 1 orang (20\%), Cemas Sedang sebanyak 6 orang (60\%), Cemas Berat sebanyak 3 orang (30\%), setelah dilakukan intervensi kecemasan ibu hamil menghadapi persalinan adalah Tidak Cemas sebanyak 3 orang (30\%), Cemas Ringan sebanyak 7 orang (70\%)

\section{Analisa Bivariat}

Tabel 2. Pengaruh Video Persalinan Normal Terhadap Kecemasan Ibu Hamil Menghadapi Persalinan Di Wilayah

Kerja Puskesmas Pangaribuan Kecamatan Pangaribuan Kabupaten Tapanuli Utara

\begin{tabular}{lrr}
\multicolumn{2}{c}{ Kabupaten Tapanuli Utara } \\
\hline \multicolumn{3}{c}{ Uji Wilcoxon Ranks Test } \\
\hline$Z$ & PostTest - PreTest \\
\hline Nilai Sig & $-2.762^{\mathrm{a}}$ \\
\hline
\end{tabular}

Berdasarkan tabel diatas dapat dilihat bahwa nilai Signifikan $=0,006<0,05$, dapat disimpulkan bahwa ada Pengaruh Video Persalinan Normal Terhadap Kecemasan Ibu Hamil Menghadapi Persalinan Di Wilayah Kerja Puskesmas Pangaribuan Kecamatan Pangaribuan Kabupaten Tapanuli Utara

\section{Pembahasan}

Berdasarkan hasil penelitian dengan menggunakan Uji Wilcoxon Rank Test didapat nilai p value 0,006 < 0,05 artinya ada Pengaruh Video Persalinan Normal Terhadap Kecemasan Ibu Hamil Menghadapi Persalinan Di Wilayah Kerja Puskesmas Pangaribuan Kabupaten Tapanuli Utara. Hasil penelitian ini menujukkan kecemasan ibu hamil sebelum menonton video persalinan normal mayoritas cemas sedang dan setelah menonton video persalinan normal mayoritas ibu hamil mengalami cemas ringan.

Kecemasan ibu hamil primigravida meningkat pada saat ibu hamil berada di trimester III saat menjelang persalinan, maka kecemasan itu sangat perlu dihindari karena akan berpengaruh bagi kesehatan ibu dan janin. Video persalinan yang dimaksud yaitu video yang berisikan proses persalinan normal yang dapat digunakan sebagai ilmu visiualisasi keadaan bagaimana sebenarnya proses melahirkan tersebut berlangsung atau terjadi. Proses kelahiran terjadi dapat dilihat melalui video persalinan normal, video ini berisikan tentang cara mudah melahirkan, lebih santai dan mengurangi nyeri persalianan serta menurunkan kecemasan menghadapi persalianan. (Walangadi N, 2014)

Menurut asumsi peneliti bahwa rasa cemas pada setiap ibu hamil itu berbeda- beda tingkatannya, namun mayoritas ibu pasti mengalami kecemasan menjelang persalinan. Kecemasan ibu hamil dapat meningkat ketika ibu sudah berada pada tahap menjelang persalinan, mayoritas mengatakan cemas sedang sedangkan setelah menonton video persalinan, dan mayoritas mengatakan menjadi cemas ringan dan ada yang mengatakan tidak cemas. Peneliti menyadari bahwa lewat adanya video persalinan maka gambaran akan tahap-tahap maupun proses persalinan itu sudah disampaikan pada ibu hamil sehingga mempermudah pemahaman ibu tentang makna persalinan sesungguhnya. Rasa cemas pun berkurang, tingkat kepercayaan ibu melahirkan dengan normal semakin baik, psikologis ibu juga baik dan energi ini memberikan dampak positif untuk persalinann yang akan dilaluinya. Video persalinan ini disampaikan dalam bentuk audiovisual yaitu gambar, suara tentang proses persalinan mulai dari kala I- kala IV yang mana hal ini menunjukkan keadaan tentang persalinan yang akan dihadapi oleh ibu nantinya. Video ini menunjukkan tahapan- tahapan persalinan yang berlangsung sehingga muncul di dalam benak ibu bahwa persalinan itu adalh hal yang alami. Menonton video persalinan normal responden menjadi lebih mengetahui tahapan-tahapan 
Indah Dewi Sari dan Sulastri Pakpahan, Pengaruh Video Persalinan Normal terhadap Kecemasan Ibu Hamil Menghadapi Persalinan di Wilayah Kerja Puskesmas Pangaribuan Kecamatan Pangaribuan Kabupaten Tapanuli Utara

persalinan sehingga mengurangi tingkat beban kecemasan mereka.

Hasil penelitian Arafah dkk tentang Kecemasan Ibu Primigravida Dalam Menghadapi Persalinan Di Klinik $\mathrm{Hj}$. Hadijah Medan setelah menonton video proses persalinan normal mengatakan ada perbedaan tingkat kecemasn ibu primigravida dalam menghadapi persalinan. Menonton video persalinan dapat menurunkan kecemasan pada ibu hamil dalam menghadapi persalinan.

\section{SIMPULAN}

Hasil penelitian yang dilakukan di Wilayah Kerja Puskesmas Pangaribuan Kabupaten Tapanuli Utara tentang pengaruh video persalinan normal terhadap kecemasan ibu hamil menghadapi persalinan, yaitu ada pengaruh video persalianan normal terhadap kecemasan menghadapi persalianan . Saran Bagi petugas pelayanan kesehatan agar memberikan pendidikan kesehatan baik itu konseling atau meberikan audiovisual tentang video proses persalinan kepada ibu primigravida dalam menghadapi persalinan sehingga dapat mengurangi rasa ketakutan dan tingkat kecemasan ibu hamil menjelang persalinannya

\section{DAFTAR PUSTAKA}

Arafah CT, \& Aizar E. (2012). Kecemasan Ibu Primigravida Dalam Menghadapi Persalinan Di Klinik Hj.Hadijah Medan Setelah Menonton Video Proses Persalinan Normal. J Keperawatan Klin. 3(1).

Kedokteran F, Katolik U, Mandala W. (2014). Hubungan Dukungan Suami Dengan Tingkat Kecemasan Menghadapi Persalinan Pada Ibu Hamil Primigravida Trimester III Di Puskesmas Mlati II Sleman.

Kartikasari E, Hernawily, Halim A. (2015). Hubungan Pendampingan Keluarga Dengan Tingkat Kecemasan Ibu Primigravida Dalam Menghadapi Proses Persalinan. J Keperawatan ISSN 19070357 ;XI(2):250-7.

Lagora R, Dewi R, (2014). Kesehatan P, Kesehatan K, Kebidanan J. Pengaruh Video Proses Persalinan Normal Terhadap Kecemasan Ibu Hamil Menghadapi Persalinan.

Dinkes P. Profil Kesehatan Sumatera Utara (2018). Kementrian Kesehat Republik Indones ;1-100.

Pengantar K. Kabupaten Tapanuli Utara Dinas Kesehatan. (2018)

Hayati F. (2018)Perbedaan Tingkat Kecemasan Ibu Bersalin Di Puskesmas Dengan Di Bidan Praktik Mandiri. J Akad Baiturrahim Jambi. 7(1):85.

Walangadi N, Kundre R, \& Silolonga W. (2014). Hubungan Pengetahuan Ibu Hamil Primigravida Trimester Iii Dengan Tingkat Kecemasan Ibu Menghadapi Persalinandi Poli Kia Puskesmas Tuminting. J Keperawatan UNSRAT.
2(2): 108741 .

Notoatmodjo S. (2016). Metodologi Penelitian Kesehatan. Jakarta: PT. Rineka Cipta 